\title{
Factors affecting the behavior of children with ASD during the first outbreak of the COVID-19 pandemic
}

\author{
Alicia Nuñez ${ }^{1,2}$ - Catalina Le Roy ${ }^{3}$ - María Elisa Coelho-Medeiros ${ }^{4}$ Mauricio López-Espejo ${ }^{1,2}$ (D)
}

Received: 24 January 2021 / Accepted: 22 February 2021 / Published online: 28 February 2021

(C) Fondazione Società Italiana di Neurologia 2021

\begin{abstract}
Aim and methods Cross-sectional data from 118 Chilean children with ASD collected during the pandemic outbreak of COVID19 in 2020 were evaluated to analyze predictors of behavioral problem impairment.

Results Forty-five percent of parents stated that their children's behavioral difficulties increased in intensity or frequency. The adjusted predictors were having a family member hospitalized with COVID-19 (OR = 4.11; 95\% CI = 1.53-11.1) and parents' mental health disorders during the pandemic ( $\mathrm{OR}=2.43 ; 95 \% \mathrm{CI}=1.01-5.83)$.

Conclusion Potentially modifiable psychosocial factors affecting children's behavior should be considered in a possible second outbreak.
\end{abstract}

Keywords Autism spectrum disorder $\cdot$ Behavior disorder $\cdot$ COVID-19 $\cdot$ Risk factors

\section{Introduction}

Autistic traits usually begin in the first years of life but may not become entirely evident until social demands exceed individual communicative abilities. Hence, to avoid anxiety and behavioral alterations, individuals with ASD have a preference for stable surroundings and structured routines. In this sense, unexpected

Mauricio López-Espejo

mlopeze@med.puc.cl

Alicia Nuñez

anunezf@uc.cl

Catalina Le Roy

catalinaleroy@yahoo.es

María Elisa Coelho-Medeiros

elisamedeiros@gmail.com

1 Unit of Neurology, Division of Pediatrics, School of Medicine, Pontificia Universidad Católica de Chile, Santiago, Chile

2 Neurodevelopment Unit, UC CHRISTUS Clinical Hospital, Santiago, Chile

3 Department of Pediatric Gastroenterology and Nutrition, Division of Pediatrics, School of Medicine, Pontificia Universidad Católica de Chile, Santiago, Chile

4 Unit of Child and Adolescent Psychiatry, Department of Psychiatry, School of Medicine, Pontificia Universidad Católica de Chile, Santiago, Chile environmental challenges may likely lead to alterations in familiar relationships, daily functioning, and biological cycles [1].

Unquestionably, a worldwide sanitary crisis such as the current pandemic brings about significant changes to the community's regular activities. During the first pandemic outbreak, Chile was one of the Latin American countries with the largest number of confirmed cases of COVID-19 [2]. As a result, health authorities have instructed extended mandatory quarantine periods, limiting personal mobility and impeding access to social spaces, including schools, non-emergency developmental and rehabilitation centers, and other public places. Besides, families were forced to adapt their lives in accordance with these restrictions, including home-based working and schooling.

As mentioned above, change in routine is often a major challenge for children with ASD; therefore, they are vulnerable to developing behavioral disorders during the quarantine [3]. This study aims to assess the impact of the first pandemic outbreak of COVID-19 on the intensity and frequency of behavioral problems (BP) of Chilean children with ASD.

\section{Methodology}

In this cross-sectional study, 152 parents of children and adolescents with ASD followed at UC-CHRISTUS Health Network, Santiago, Chile, were invited to answer an online 
survey during the pandemic through Google Forms. The questionnaire was available online from August 1 to October 30, 2020. All evaluated patients (aged 2 to 15 years) had ASD diagnosis, according to DSM 5 criteria [4], with an Autism Diagnostic Observation Schedule, second edition (ADOS-2) scoring above the diagnostic cutoff [5]. Children and adolescents with developmental abnormalities due to a demonstrated chromosome disorder or monogenic mutation were excluded. The institutional ethics committee approved the study (CECMedUC: 200617027), and each child or adolescent caregivers gave informed consent. An informative first paragraph explained the aim of the study and informed caregivers of ethical approval. Collected data remained anonymized and securely protected during research.
A national multidisciplinary expert panel evaluated an adapted survey applying the modified DELPHI method $[6,7]$. After two rounds of online consultation to enhance the decision-making process and clarify the language used to describe each item, the consensus among experts was over $80 \%$ for relevance and wording quality agreement. The survey instrument was formulated to rate behavioral impact on children with ASD during the first pandemic outbreak of COVID-19, applying yes or no questions or multiple-choice questions using a 3-point Likert scale based on intensity and frequency of BP (more, equal, and less than before the pandemic).

All statistical analyses were performed using the IBM SPSS Statistics version 23 (Armonk, NY: IBM Corp.)

Table 1 Univariate predictors for increased intensity and frequency of children's behavioral difficulties during the pandemic outbreak $(n=118)$

\begin{tabular}{|c|c|c|c|c|}
\hline Studied variables & $\begin{array}{l}\operatorname{IBD}(n) / \text { with variable }(n) \text { vs. } \operatorname{IBD}(n) / \\
\text { without variable }(n)\end{array}$ & OR & $(95 \% \mathrm{CI})$ & $p$ value \\
\hline \multicolumn{5}{|l|}{ Demographics } \\
\hline Male gender & $46 / 95$ vs. $7 / 23$ & 2.15 & $(0.81-5.69)$ & 0.125 \\
\hline Age (years) & Continuous variable & 0.98 & $(0.87-1.10)$ & 0.673 \\
\hline Age $<6$ years & $26 / 52$ vs. $27 / 66$ & 1.44 & $(0.69-3.00)$ & 0.325 \\
\hline Living in the capital city & $39 / 83$ vs. $14 / 35$ & 1.33 & $(0.60-2.97)$ & 0.486 \\
\hline Residence with backyard or garden & $51 / 109$ vs. $2 / 9$ & 3.10 & $(0.61-15.5)$ & 0.173 \\
\hline Living with both parents & $38 / 90$ vs. $15 / 28$ & 0.63 & $(0.27-1.49)$ & 0.294 \\
\hline Living with a single parent & $15 / 25$ vs. $38 / 93$ & 2.17 & $(0.88-5.34)$ & 0.092 \\
\hline Living with extended family & $19 / 36$ vs. $34 / 82$ & 1.58 & $(0.72-3.47)$ & 0.257 \\
\hline Living with other children & $25 / 64$ vs. $28 / 54$ & 0.60 & $(0.29-1.24)$ & 0.165 \\
\hline Living with an individual with ASD & $13 / 25$ vs. $40 / 93$ & 1.44 & $(0.59-3.48)$ & 0.424 \\
\hline Therapy before the pandemic & 49/110 vs. $4 / 4$ & 0.80 & $(0.19-3.38)$ & 0.765 \\
\hline Daycare or school before the pandemic & $52 / 113$ vs. $1 / 5$ & 3.41 & $(0.37-31.5)$ & 0.279 \\
\hline Therapy during the pandemic & $27 / 67$ vs. $26 / 51$ & 0.65 & $(0.31-1.35)$ & 0.249 \\
\hline Daycare or school during the pandemic & $46 / 94$ vs. $7 / 24$ & 2.33 & $(0.88-6.13)$ & 0.087 \\
\hline Death of someone close to the child & $12 / 22$ vs. $41 / 96$ & 1.61 & $(0.63-4.09)$ & 0.317 \\
\hline Parent mental health problems & $18 / 30$ vs. $35 / 88$ & 2.27 & $(0.98-5.29)$ & $0.057^{\mathrm{a}}$ \\
\hline Pandemic-related unemployment of parents & $9 / 15$ vs. $44 / 103$ & 2.01 & $(0.67-6.07)$ & 0.215 \\
\hline Home-based telework of parents & $29 / 74$ vs. $24 / 44$ & 0.54 & $(0.25-1.14)$ & 0.107 \\
\hline \multicolumn{5}{|l|}{ Clinical characteristics } \\
\hline Absence of verbal language & $5 / 13$ vs. $48 / 105$ & 0.74 & $(0.23-2.42)$ & 0.621 \\
\hline Effortless fluent speech & $27 / 61$ vs. $26 / 57$ & 0.95 & $(0.46-1.96)$ & 0.883 \\
\hline Behavioral problems before the pandemic & $38 / 72$ vs. $15 / 46$ & 2.31 & $(1.07-4.99)$ & 0.033 \\
\hline Other medical condition & $8 / 26$ vs. $45 / 92$ & 0.46 & $(0.18-1.17)$ & 0.105 \\
\hline \multicolumn{5}{|l|}{ COVID-19 related features } \\
\hline Household member with COVID-19 & $2 / 9$ vs. $51 / 109$ & 0.33 & $(0.07-1.64)$ & 0.173 \\
\hline Family member with COVID-19 & $26 / 52$ vs. $27 / 66$ & 1.44 & $(0.69-3.00)$ & 0.325 \\
\hline Family member hospitalized with COVID-19 & $17 / 24$ vs. $36 / 94$ & 3.91 & $(1.48-10.4)$ & $0.006^{\mathrm{a}}$ \\
\hline Family member deceased by COVID-19 & $6 / 10$ vs. $47 / 108$ & 1.95 & $(0.52-7.30)$ & 0.323 \\
\hline
\end{tabular}

$I B D$ increased intensity and frequency of children's behavioral difficulties. *OR for age is per 1-year increase in age. ${ }^{*}$ Statistically significant in multivariable analysis 
software. Continuous data were reported as median and interquartile ranges (IQRs), while categorical data were reported as absolute and relative frequencies. We used Fisher's exact test for associations between dichotomous variables. A forward, stepwise multiple logistic regression model was performed to investigate clinical and socio-demographic predictors for higher frequency and intensity of BP, including all variables with a $p$ value $<0.1$ in the univariate analysis (significance set at $5 \%$; results presented as odds ratios (OR) with $95 \%$ confidence intervals $(\mathrm{CI})$ ).

\section{Results}

Among 152 total participants who met the inclusion criteria, $118(77 \%)$ participated in the survey. In $76.3 \%$ of the cases, the mother answered the questionnaire; in $7 \%$, it was the father who answered. In $21 \%$, both parents answered the survey together. Of 118 children with ASD, 94 (79.7\%) were boys, and $24(20.3 \%)$ were girls. The median age at survey realization was 6 years (IQR, 4-8), and the median age at ASD diagnosis was 3 years (IQR, 2-5). Baseline characteristics of studied children are summarized in Table 1.

Among the parents who responded, $44.9 \%$ stated that the BP of their children increased in intensity or frequency during the pandemic (Table 1). Following a forward, stepwise logistic regression analysis, the predictors of increased intensity and frequency of BP during the pandemic were having a family member hospitalized with COVID-19 (OR $=4.11 ; 95 \% \mathrm{CI}$ $=1.53-11.1)$ and parents' mental health disorders during the pandemic $(\mathrm{OR}=2.43 ; 95 \% \mathrm{CI}=1.01-5.83)$.

\section{Discussion}

Our findings confirm that children and adolescents with ASD increased the frequency and intensity of BP during the first outbreak of the COVID-19 pandemic, offering results replication of a previous study conducted by Colizzi et al [6]. According to parent-reported data, both mental health disorders of caregivers who had a close one hospitalized due to COVID are independent risk factors for increased BP in evaluated children.

Although social distancing has generated a significant psychosocial burden among individuals, the impact on mental health has been poorly considered during the pandemic, especially in high-risk groups [8]. It was expected that patients with ASD exacerbate their clinical symptoms during the pandemic. Our results show that almost half of the participants perceived that their children's BP increased during this first outbreak. In this line, a recent parent-survey-based study indicates that over one-third of the caregivers of individuals with
ASD recognize the pandemic changes as a cause of worsening $\mathrm{BP}$ in their children [6].

As a previous report from which we adapted our survey, children with behavioral difficulties before the pandemic have a considerably increased intensity and frequency of BP than those without this antecedent $(44.4 \%$ vs. $32.6 \%$ ) [6]. The pre-existence of mental health disorders among parents predicts children's behavior worsening during the quarantine, in line with a study showing that parents' mental health difficulties predicted concurrent children mental health problems in the short-term [9]. Finally, COVID-19's direct impact is reflected in the behavioral changes observed in children who have a family member hospitalized for the disease, presumably due to stress on the family system as a whole.

Understanding features associated with increased BP in children with ASD during the first outbreak may help prevent child and family psychosocial health impairment during a further prolonged quarantine period. In this sense, the current study results show that both children and family environmental factors affect the frequency and intensity of BP.

Supplementary Information The online version contains supplementary material available at https://doi.org/10.1007/s10072-021-05147-9.

\section{Declarations}

Ethical approval The institutional ethics committee approved the study (CEC-MedUC: 200617027).

Conflict interest The authors declare that there is no conflict of interest. Supplementary Information The online version contains supplementary material available at https://doi.org/10.1007/s10072-021-05147-9.

\section{References}

1. Ashburner J, Bennett L, Rodger S, Ziviani J (2013) Understanding the sensory experiences of young people with autism spectrum disorder: a preliminary investigation. Aust Occup Ther J 60(3):171180. https://doi.org/10.1111/1440-1630.12025

2. W.H.O Coronavirus Disease (COVID-19) Pandemic. [(accessed on 26 Dec 2020)]; Available online: https://www.who.int/emergencies/ diseases/novel-coronavirus-2019.

3. Amorim R, Catarino S, Miragaia P, Ferreras C, Viana V, Guardiano M (2020) The impact of COVID-19 on children with autism spectrum disorder. Impacto de la COVID-19 en niños con trastorno del espectro autista. Rev Neurol 71(8):285-291. https://doi.org/10. 33588/rn.7108.2020381

4. American Psychiatric Association (2013) Diagnostic and statistical manual of mental disorders, 5th edn. American Psychiatric Association, Arlington, VA

5. Lord C, Rutter M, DiLavore P, Risi S, Gotham K, Bishop SL (2012b) Autism Diagnostic Observation Schedule, Second Edition (ADOS-2) Manual (Part I): Modules 1-4. Western Psychological Services, Torrance, CA 
6. Colizzi M, Sironi E, Antonini F, Ciceri ML, Bovo C, Zoccante L (2020) Psychosocial and behavioral impact of COVID-19 in autism spectrum disorder: an online parent survey. Brain Sci 10(6):341. Published 2020 Jun 3 10.3390/brainsci10060341

7. Hasson F, Keeney S, McKenna H (2000) Research guidelines for the Delphi survey technique. J Adv Nurs 32(4):1008-1015

8. Giallonardo V, Sampogna G, Del Vecchio V et al (2020) The impact of quarantine and physical distancing following COVID-19 on mental health: study protocol of a multicentric italian population trial.
Front Psychiatry 11:533. Published 2020 Jun 5. https://doi.org/10. 3389/fpsyt.2020.00533

9. Crea K, Dissanayake C, Hudry K (2016) Proband mental health difficulties and parental stress predict mental health in toddlers at high-risk for autism spectrum disorders. J Autism Dev Disord 46(10):3242-3257. https://doi.org/10.1007/s10803-016-2861-y

Publisher's note Springer Nature remains neutral with regard to jurisdictional claims in published maps and institutional affiliations. 